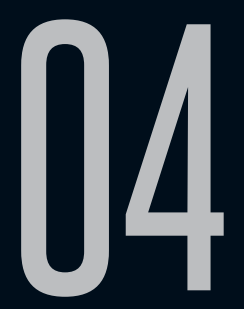

\title{
MINICONTO E ABJEÇÃO: A PASSAGEM DE FRONTEIRAS
}

Mariana Silva Franzim (UEL)

Recebido em 22 mai 2018. Mariana Silva Franzim é Graduada em Artes Visuais Aprovado em 27 ago 2018. pela Universidade Estadual de Londrina, especialista em Ilustração pela Universidade Norte do Paraná, Mestra e Doutoranda em Estudos Literários pela Universidade Estadual de Londrina. Docente nos cursos de graduação em Artes Visuais, Design e Arquitetura na Universidade Norte do Paraná, Universidade Anhanguera e Universidade Estadual de Londrina.

Resumo: No presente artigo iremos analisar a presença da abjeção no miniconto brasileiro contemporâneo. Refletiremos brevemente acerca da teoria do conto e do miniconto traçando um paralelo com o conceito de abjeção a partir de Julia Kristeva e Marcio SeligmannSilva. A partir dessa reflexão, nos voltaremos para a análise da presença abjeta no miniconto "Os inocentes" de Rubem Fonseca e no texto "Ele canta" de Nuno Ramos. Por fim buscaremos demonstrar a pertinência entre o conteúdo da abjeção e a forma do miniconto.

Palavras-chave: Insólito; Miniconto; Abjeção; Rubem Fonseca; Nuno Ramos.

Abstract: In the present paper we will analyse the presence of abjection in Brazilian flash fiction. We 
will reflect on the theory of the short story and the flash fiction drawing a parallel with the concept of abjection from Julia Kristeva and Marcio SeligmannSilva. From this reflection we will analyse the abject presence in the flash fiction "Os Inocentes" by Rubem Fonseca and in the text "Ele canta" by Nuno Ramos. In conclusion we will demonstrate the pertinence between the theory of the abjection and the form of the flash fiction.

Keywords: Unusual; Flash Fiction; Abjection; Rubem Fonseca; Nuno Ramos.

"O belo é podre e o podre, belo pode ser. Ambos pairam na cerração e na imundície do ar" (William Shakespeare/Macbeth)

No presente trabalho nos propomos a analisar comparativamente dois textos de autores brasileiros que não são comumente atrelados à literatura fantástica: Rubem Fonseca e Nuno Ramos. Conforme atestaremos ao longo da nossa reflexão, pontos centrais do fantástico contemporâneo podem ser problematizados a partir de determinados textos dos autores em questão.

Remo Ceserani, em O Fantástico (2006), ao apresentar uma breve história da análise crítica dedicada ao fantástico entendido enquanto forma literária iniciada no século XIX, mostra duas principais tendências críticas. A primeira, tendo como principal representante o estruturalista Tzvetan Todorov, chega a uma definição fechada do fantástico enquanto gênero, tendo como principal parâmetro para análise elementos intratextuais. Contraposta a esta, e aqui representada por Irène Bessière, há outra vertente crítica exposta por Ceserani. Essa, mais aberta, postula que o fantástico, enquanto forma ou modo, abarca uma ampla gama de 
gêneros, não se restringindo a limitações regionalistas ou de época. Irène Bessière (Apud CESERANI, 2006) entende que não há uma linguagem fantástica por excelência, sendo assim, esta pode estar presente no seio de diversas outras linguagens. Sua existência seria afirmada pelo seu poder de desconstrução discursiva concebida a partir da ambiguidade. A autora afirma que

este elemento de desconstrução e de inversão comporta a ideia de que, diferente da narração maravilhosa, iluminista ou onírica, não se pode relacionar a narração fantástica ao universo, pois ela priva de cada significado fixado todos os símbolos [...] A narração fantástica é tética; ela enuncia a realidade daquilo que representa: condição própria da narração que intui o jogo do nada e do excesso, do negativo e do positivo. (BESSIÈRE Apud CESERANI, 2006, p.65)

Bessière não concorda com a tomada do fantástico enquanto linha divisória entre gêneros, mas o compreende "pela via da falsidade obscurecida, o lugar de convergência da narração tética (romance dos realia) e daquela não tética (maravilhoso, fábula de magia)" (BESSIÈRE Apud CESERANI, 2006, p.65). A autora contradiz a concepção que toma o fantástico redutivamente como o negativo do racionalismo iluminista. O fantástico seria conjugador de elementos opostos, não figurando a divisão, mas sim a

polivalência dos signos intelectuais e culturais. (...) O fantástico põe em relevo a distância constante do sujeito do real e por isso ele está sempre ligado às teorias sobre o conhecimento e às crenças de uma época. (...) o fantástico assinala a medida do real através da desmedida. O ceticismo que só marca a intimidade da razão e da desrazão é o 
ingrediente obrigatório do imaginável (BESSIÈRE Apud CESERANI, 2006, p.65).

Ceserani aponta que a tomada de Bessière do fantástico, enquanto modo literário, permite que este se liberte de uma delimitação temporal e possa ser identificado de maneira persistente ao longo da história da literatura. Neste trabalho iremos adotar esta segunda concepção, na qual o fantástico, entendido como modo e não como gênero, pode ser identificado em diversas obras a partir de certas similaridades que as aproximam. Entender o fantástico enquanto modo nos permite analisar obras de autores que tradicionalmente não são vinculados ao fantástico enquanto gênero, isto posto, introduziremos os autores que figuram o centro da atual investigação.

Rubem Fonseca, mineiro nascido em 1925, publica seu primeiro livro de contos em 1963. Ao longo de sua carreira produz contos, minicontos, crônicas e romances e com o passar dos anos sua obra continua atual:

Observando os caminhos tomados pelo Brasil a partir da década de 60, em que a esperança no milagre da industrialização provocou o inchaço das cidades e a geração de legiões de excluídos que rapidamente se tornaram marginais, é possível dizer que a literatura de Fonseca evidencia o próprio desenvolvimento da violência urbana no país (PELLEGRINI, 1999), indo além da temática da pobreza ao mostrar, de forma mais ampla, a vida oprimida e automatizada de qualquer classe social das cidades de homens sem nome. (GONÇALVES, 2006, p.12)

Petar Petrov reconhece três linhas temáticas na obra de Fonseca:

a da alienação generalizada, tanto dos "miseráveis sem dentes", como dos da camada à qual pertence 
a "gente fina e nobre"; a da violência exacerbada, exercida tanto pelo poder instituído como pelos marginais; a das sexualidades ilegítimas, nas suas várias manifestações, com a incidência da prostituição e da homossexualidade. (PETROV, 2000, p. 89 apud Apud GONÇALVES, 2006 p.14)

Da obra do autor selecionamos o conto "Os inocentes", que aparece na obra Lucia McCartney, publicada pela primeira vez em 1969. O livro apresenta uma seleção de contos que possuem uma linguagem irônica e dura que se assemelha à das manchetes de jornais e se direciona às angústias cotidianas de forma ácida e incisiva. "Os inocentes" é composto por pouco mais trinta linhas nas quais o autor emprega recursos que remetem aos movimentos de uma câmera cinematográfica e apresenta ao leitor uma cena onde um cadáver surge estendido aos olhos dos banhistas na areia da praia.

Nuno Ramos, nascido em São Paulo em 1960, é um artista que explora múltiplas linguagens: desenho, pintura, escultura, instalação, vídeo e a escrita. O pão do corvo, lançado em 2001, apresenta uma coletânea de estranhas narrativas curtas. O texto aqui analisado, "Ele canta", publicado na obra em questão, não se desenvolve através da narração das ações de diferentes personagens, mas sim na apresentação de um estranho e enigmático corpo. O leitor é guiado através deste corpo a partir de desconexas e ambíguas caracterizações que impedem que criemos uma imagem completa e definida a respeito da identidade do corpo descrito. A crítica de Pádua Fernandes (2004) denota a dificuldade de definição do caráter das narrativas que compõem a obra citada:

Nuno Ramos - um dos grandes artistas plásticos e poetas brasileiros - lançou seu segundo livro 
de poesia, abstrusamente classificado na ficha catalográfica como 'ficção brasileira'. Bernardo Carvalho, em sua coluna no jornal Folha de S. Paulo, conseguiu enxergar contos na prosa poética desse livro; não sei que romances veria em Pequenos poemas em prosa de Baudelaire... Chega de apropriações indébitas de gênero: $O$ pão do corvo (São Paulo: Editora 34, 2001) é um livro de poesia como o anterior Cujo (Editora 34, 1993), também escrito em prosa. Não sei a quem atribuir a apropriação, que certamente não fará diferença alguma no destino da obra no mercado; contudo, fato é que, na Folha de S. Paulo, Nuno Ramos publicou anteriormente um dos textos desse livro, 'Ele canta', em prosa como todos os outros, como poema. Ademais, não fosse poesia, o livro seria uma obra filosófica, e não ficção. (FERNANDES, 2004, p.137)

A crítica de Fernandes expõe a fragilidade das fronteiras no momento da tentativa de definição de um texto de caráter ambíguo. O descompasso entre as definições apresentadas pelo autor e por diferentes críticos demonstra que o texto resiste, de alguma forma, a cada uma das categorias a ele vinculadas. À primeira vista "Ele canta" parece possuir todos os requisitos para ser classificado enquanto um conto curto ou, como algo paradoxal, como "miniconto extenso".

Ao nos lançarmos à análise de um texto curto, percebemos logo de início a dificuldade da definição do miniconto enquanto forma literária. Uma teoria voltada para o estabelecimento do miniconto como gênero parece ainda estar em elaboração. Nas análises do miniconto, percebemos a busca da teoria do conto na tentativa de compreender e estabelecer aproximações e fronteiras entre a forma 
mais extensa e a mais curta da narração. Por conta disto, quando necessário, iremos nos apropriar de textos teóricos dedicados ao conto em busca de suporte para lidarmos também com o miniconto. Alfredo Bosi em O Conto Brasileiro Contemporâneo destaca o lugar do conto na literatura contemporânea:

Posto entre as exigências da narração realista, os apelos da fantasia e as seduções do jogo verbal, ele tem assumido formas de surpreendente variedade. Ora é o quase-documento folclórico, ora a quasecrônica da vida urbana, ora o quase-drama do cotidiano burguês, ora quase-poema do imaginário às soltas, ora, enfim, grafia brilhante e preciosa voltada às festas da linguagem (BOSI, 2002, p.7)

$\mathrm{Na}$ fala de Bosi percebemos que mesmo o conto assume uma pluralidade de formas e tem como característica a multiplicidade de temas. O miniconto encontra destaque na produção contemporânea brasileira na década de 1990 na produção de autores como Dalton Trevisan. Miguel Vieira, em Origens do miniconto brasileiro contemporâneo (2015), destaca entre os principais nomes da escrita do miniconto brasileiro contemporâneo autores como Fernando Bonassi, Ivana Arruda Leite, João Gilberto Noll, Marina Colasanti e Verônica Stigger.

Encontrar diversas denominações para os textos curtos em prosa, tal qual miniconto, microconto, microrrelato, ou poema em prosa, atesta a dificuldade da categorização de tais produções em um gênero fixo e bem definido. Ao resistirem à classificação exata, esses textos apresentam um desafio para o crítico e para o teórico, que se colocam no trabalho de atestar as dessemelhanças entre o texto analisado e as delimitações dos gêneros já bem definidos, 
aos quais o miniconto parece nunca se adequar. 0 trabalho de análise nesse sentido se torna um trabalho de negação, de apontar todos os motivos pelos quais o miniconto escapa dos moldes préestabelecidos e demanda algo para além da simples definição de gênero. Marcelo Spalding, em Os Cem Menores Contos Brasileiros do Século e a Reinvenção do Miniconto na Literatura Brasileira Contemporânea (2008) comenta a respeito desta dificuldade: "estudar positivamente o conto é sempre um grande problema devido às suas tênues fronteiras, e, como esse estudo lida com um limite estético, tal problema se torna mais evidente" (SPALDING, 2008, p.10).

Sobre o assunto, Vieira (2015) questiona: “Mas é algo, mesmo, indispensável para o miniconto, a divisão clara de procedimentos de gênero? Ou seria a hibridação um passo adiante dessa forma de textualidade, seu tom de genuinidade específica?" (p.78). O caminho apontado por Miguel Vieira nos parece até então o mais adequado, visto que, ao enquadrar determinado texto em uma definição fechada de gênero, o encerramos em uma gaveta. Encontrar uma única categorização que viesse a servir a todos os minicontos e desse conta de elucidar sua construção formal seria uma maneira de aniquilar a potência da hibridação, visto que boa parte da força de um bom miniconto parece residir justamente na ambiguidade. Justamente a ambiguidade parece ser um ponto comum encontrado entre minicontos dos mais diversos autores. A concisão exigida pela forma curta acaba por criar espaços vazios que serão preenchidos pelo leitor. Isto posto, podemos afirmar que, em uma forma de narração sucinta, as imagens e sentidos são estabelecidas tanto por aquilo que é dito quanto pelo não dito. Os 
vazios do texto são repletos de significação e potência. "Ele canta" exemplifica essa questão. Toda a força de estranhamento reside na ausência de definição do corpo apresentado no texto. Lemos uma descrição de algo que nunca saberemos o que é. O narrador nos priva de um nome, de uma espécie. Cada frase que se segue despeja sobre o leitor uma série de informações que acaba por afastá-lo cada vez mais do ponto-chave: o que é esse corpo? Quanto mais sabemos dele, menos nos sentimos capazes de nomeá-lo, mais aumenta o vazio entre nós e ele.

Em um texto em que muito pouco é dito, sua força deve residir em determinados detalhes e estratégias que tomem o leitor de assalto. Já nas teorias do conto aparece a exigência de uma intensificação do fato narrado. A fim de alcançar o arrebatamento do leitor, o contista deve se valer de alguns artifícios. Cortázar (2004) analisa três categorias próprias do conto relacionadas aos seus efeitos no leitor: a significação, intensidade e tensão. A significação do conto está relacionada à ordem temática. Para pensar acerca do tema, Cortázar se propõe a ir até o momento anterior ao surgimento do conto. Para que um bom conto seja realizado é necessário que seu tema seja excepcional. O autor explica: "O excepcional reside numa qualidade parecida à do ímã; um bom tema atrai todo um sistema de relações conexas, coagula no autor, e mais tarde do leitor" (CORTÁZAR, 2004, p.154). Para Cortázar deve haver um "sequestro momentâneo do leitor" (CORTÁZAR, 2004, p.157), o qual se dá pelo o que o autor define enquanto ofício do escritor que produz os efeitos de intensidade e tensão. A intensidade tem a ver com a eliminação de tudo aquilo que excede ao essencial da trama e está diretamente relacionada à ação. A tensão é outra ordem de 
intensidade e se liga a uma aproximação lenta da situação central e à criação de uma certa atmosfera. No miniconto, porém, não há espaço para tal lentidão, o autor necessita encontrar meios para instaurar a tensão logo nas primeiras palavras.

Ceserani (2006) busca em Roger Caillois uma definição do fantástico como a manifestação de

um escândalo, uma laceração, uma irrupção insólita, quase insuportável, no mundo da realidade [...] O fantástico é, assim, ruptura da ordem reconhecida, irrupção do inadmissível dentro da inalterável legalidade cotidiana, e não substituição total de um universo real por um exclusivamente fantasioso (CAILLOIS, Apud CESERANI, 2006, p.47).

Caillois entende como procedimento central do fantástico a aparição. O autor define que só é possível a manifestação do fantástico em um universo previsível e banal, tido como salvo de qualquer espécie de mistério. Nesse universo, subitamente ocorre a manifestação do inadmissível, tal aparição é aquilo "que não pode aparecer, mas aparece" (CAILLOIS, Apud CESERANI, 2006, p.47). Partindo do estudo de Caillois, Louis Vax propõe o inexplicável como central na formulação do fantástico. Assim introduz a noção do 'conflito' entre 'real' e 'possível'; introduz enfim a ideia de que o fantástico contém em si um forte elemento de 'sedução'” (CESERANI, 2006, p.47).

Em "Os inocentes" o leitor já é tomado de surpresa nas primeiras linhas do texto, quando algo de incomum se revela: "O mar tem jogado na praia pinguim,/ [tartaruga gigante, cação, cachalote./ Hoje: mulher nua" (FONSECA, 1999, p.171). O mesmo acontece em "Ele canta", a curiosidade do leitor é ativada logo nas 
duas primeiras frases: "Não pode tocar. Acho que ainda está mole e vivo" (RAMOS, 2001, p.13). A tensão está relacionada àquilo que é interno à narrativa. Cortázar liga as duas categorias, intensidade e tensão, afirmando que ao elaborar um bom conto é necessário "escrever tensamente, mostrar intensamente" (CORTÁZAR, 2004, p.159). O ficcionista deve escrever tendo em vista a criação da atmosfera e de determinadas situações ao mesmo tempo em que deve mostrar apenas aquilo que esteja diretamente ligado à ação. A fim de refletir acerca de uma construção textual na qual a narração e a ação devam coincidir tanto quanto possível, tendo em vista gerar um abalo no leitor a partir de uma linguagem sucinta, tomamos emprestado o que escreveu Alexandre Eulálio ao analisar a produção do contista mineiro Murilo Rubião (1916 - 1991):

Na linguagem, esse elemento monstruoso se insinua pé ante pé, através da deformação cuidadosa da frase corrente, cuja sobriedade ostensiva vai sendo aos poucos desgastada pelo sinônimo raro, pelo termo técnico, pela palavra exata demais, que abrem na oração aparentemente sem recursos a trilha para o elemento insólito. A dosagem sábia dessas mutações quase imperceptíveis pode acelerar-se até à mesma explosão da frase. Colocando em questão a própria univocidade vocabular e conceitual, acaba por desmembrar o raciocínio lógico com o mesmo minucioso furor frio do menino que destroça um inseto - primeiro uma asa, depois uma pata, depois uma antena - até que o raciocínio 'roto, baço, vil' sucumbe de vez. (EULÁLIO, 1965, p.3)

A bela imagem do destroçar um inseto pode também funcionar como metáfora do trabalho empreendido por Rubem Fonseca em seus 
minicontos. Rachel Gonçalves, em sua dissertação "Pequenas criaturas e o efeito do real: a estética da crueldade em Rubem Fonseca" (2006), caracteriza seu texto enquanto "cru, sintético e brutal" (GONÇALVES, 2006, p.9). A escrita de Fonseca acaba por produzir um efeito único no leitor, que, após a leitura, se vê tomado por um estranho incômodo gerado pelo texto. A fim de elucidar o efeito gerado por uma boa narrativa curta, podemos resgatar o comentário de Cortázar: "Os contos dessa espécie incorporam-se como cicatrizes indeléveis em todo leitor que os mereça: são criaturas vivas, organismos completos, ciclos fechados, e respiram. Eles respiram, não o narrador" (CORTÁZAR, 2004, p.235 - grifo do autor).

A afirmação de Cortázar aponta para uma característica muito específica das narrativas curtas: a viscosidade. Obras como a de Fonseca e a de Nuno Ramos apresentam uma construção formal e temática que atingem em cheio o leitor. Não há como se manter impune após a leitura de suas obras. Mesmo depois de fechadas as páginas do livro, algo de incômodo parece ter se arrastado das letras impressas em direção ao leitor e o acompanha indefinidamente. Para refletirmos acerca do estranho efeito causado pelos recursos empregados nos textos desta categoria, iremos buscar as teorias acerca da abjeção.

Já no final do século XVIII, Friedrich Schiller constata que "é um fenômeno geral na nossa natureza que aquilo que é triste, terrível e até horrendo nos atraia com irresistível fascínio; que nos sintamos repelidos e atraídos com a mesma força por cenas de dor e de terror" (SCHILLER, Apud ECO, 2007, p.279). Umberto Eco, em A História da Feiura (2007), enumera os horrores que vemos no nosso cotidiano: imagens da fome, violência urbana, atos de terrorismo, 
cenas de guerra, do holocausto e conclui que nesses casos estamos frente ao feio moral e físico, situações nas quais:

Nenhuma consciência da relatividade dos valores estéticos elimina o fato de que, nestes casos, reconhecemos sem hesitação o feio e não conseguimos transformá-lo em objeto de prazer. Compreendemos então porque a arte dos vários séculos tem voltado com tanta insistência a representar o feio. Por mais marginal que seja, sua voz tenta recordar que há neste mundo algo de irredutível e maligno. (ECO, 2017, p.436)

É justamente esta a temática que povoa a obra de Rubem Fonseca:

$\mathrm{Na}$ linha que Antonio Candido e Alfredo Bosi denominaram realismo feroz (BOSI, 1975), Fonseca vale-se de dicção rápida e traço forte para mostrar de forma incisiva, seca e dolorosa a brutalidade que se apresenta de diversas formas nos países subdesenvolvidos e tecnocratas: revela-se em sua prosa de ficção a miséria econômica, as explosões violentas de vingança do marginal, a busca pela sobrevivência, o apagamento da individualidade que cede lugar às máscaras sociais, à reificação do indivíduo. (GONÇALVES, 2006, p.8)

Tais temáticas nos remetem àquelas exploradas através das teorias da abjeção. Em O local da diferença (2005), Márcio Seligmann-Silva analisa a estética do sublime, da abjeção e do papel da dor na arte contemporânea. A partir dessa obra é possível notar a maneira pela qual as teorias do sublime foram subvertidas através do tempo resultando em uma estética do abjeto. A noção da abjeção, tal como é teorizada pela psicanalista Julia Kristeva (1980), se faz fundamental para a análise da produção das artes visuais e da literatura contemporânea. 
Conforme aponta Seligmann-Silva, é possível encontrar já em Aristóteles o início de uma reflexão sobre o tema em questão. 0 filósofo já afirmava que "das coisas cuja visão é penosa temos prazer em contemplar a imagem quanto mais perfeita; por exemplo, as formas dos bichos mais despreziveis e dos cadáveres" (SELIGMANNSILVA, 2005, p.31). Seligmann-Silva aponta, a partir da teoria do filósofo iluminista alemão Moses Mendelssohn (1729 - 1786), "a importância do abalo que a obra de arte deveria gerar no seu receptor" (SELIGMANNSILVA, 2005, p.36). A perda dos sentidos gerada no espectador deveria atuar "como um desvio da norma e como algo que nos leva para fora de nós mesmos; algo para o qual 'não temos palavras'" (SELIGMANNSILVA, 2005, p.35). Essa noção nos remete diretamente aos efeitos que Cortázar exige do bom conto.

Seligmann-Silva percebe que a partir da modernidade o abalo gerado pela obra de arte se relaciona diretamente com a condição do homem:

o homem moderno é o homem que deseja, vale dizer: que não é capaz de fechar a ferida aberta no seu corpo com a separação da 'natureza'. A arte passa aos poucos a ser o campo do novo e do chocante; nela concretiza-se a busca de um abalo que é gerado por aquilo que não tem limites, [...] 0 campo da arte moderna estende-se cada vez mais - desde o final do século XVIII, ou seja: desde o Romantismo - entre o 'grito' de dor diante do realcomo-morte e o silêncio: reflexo da incapacidade de se abarcar o mundo de modo conceitual. (SELIGMANN-SILVA, 2005, p.36-37)

Deslocada a condição do homem moderno para o contemporâneo, tal noção expressa por Seligmann-Silva nos 
remete ao tratamento temático de Fonseca, destacado por Hélio Pólvora, voltado para o "homem contemporâneo em todos os seus apocalipses, desenraizado geograficamente, varrido pelas mudanças sociais, políticas e econômicas ainda não sedimentadas inteiramente em todas as suas consequências" (PÓLVORA, 1971, p.38-39).

A principal teórica a debruçar-se sobre o conceito do abjeto é a psicanalista Julia Kristeva na obra Pouvoirs de I'horreur: Essai sur l'abjection (1980). A partir desta é definido que "o abjeto não é o objeto, é uma espécie de primeiro não-eu, uma negação violenta que instaura o eu; trata-se em suma de uma fronteira" (SELIGMANNSILVA, 2005, p.36). A fim de compreender a delimitação do conceito de abjeção é interessante buscar as aproximações e dessemelhanças apontadas por Seligmann-Silva entre o sublime e o abjeto, sendo este último considerado

um não-sentido que nos oprime - assim como o sublime é um sobre-sentido que nos escapa. Diferente do sublime, a manifestação privilegiada do abjeto é o cadáver [...] A abjeção, não obstante, assim como o sublime também está intimamente ligada à falta: ela revela a falta como fundadora do ser; e, ainda, tal como o sublime, ela nos amedronta [...] Como o sublime, também o abjeto é uma manifestação de uma ausência de limite - mas diferente dele, a abjeção representa esse não-limite, por assim dizer, 'para baixo'. (SELIGMANN-SILVA, 2005, p.39-40)

Considerando que ambos os conceitos referem-se ao inominável e ao sem-limites, é possível notar seu distanciamento ao perceber que o sublime está ligado ao espiritual "e o abjeto ao corpo. 
Ambos são conceitos de fronteira marcados pela ambiguidade e que nos abalam: o abjeto nos remete para baixo - cadáver, vem do latim cadere, cair: um corpo que cai." (SELIGMANN-SILVA, 2005, p.40 - grifo do autor). 0 autor também destaca que a função das manifestações do abjeto nas artes seria a de "violentar os limites - os tabus [...] Uma das características marcantes dessa arte abjeta seria o voyeurisme" (SELIGMANN-SILVA, 2005, p.40 - grifo do autor). Tanto no texto selecionado de Fonseca quanto no de Nuno Ramos, o narrador assume uma posição semelhante a do voyeur, carregando o leitor com ele. Ao acessar o texto são apresentados ao leitor os pormenores vislumbrados por um olhar que percorre curiosamente a superfície de um corpo.

Seligmann-Silva define "a teoria do abjeto como escritura do corpo enquanto elemento central da nossa contemporaneidade" (2005, p.42). Definir a presença do corpo na arte como suporte para a fruição estética faz com que alcancemos o contrário do anunciado por Gotthold Ephraim Lessing em Laocoonte, ou sobre as fronteiras da pintura e da poesia (1766), obra que delimita a representação da dor enquanto um limite para que uma escultura fosse considerada ou não uma obra de arte. Se antes o extremo, o chocante e o asqueroso estavam situados fora do campo das artes "agora o extremo é a regra [...] o que conta agora é justamente o anti-ilusionismo do asqueroso como realidade tout court. Ele bloqueia a nossa imaginação, mas estimula a nossa reflexão" (SELIGMANN-SILVA, 2005, p.42-43 - grifo do autor). Distante dos limites estabelecidos pela noção de Belo renascentista e em consequência da mudança de paradigma iniciada com a estética do sublime, 
a verdade parece residir agora no trauma: no corpo como anteparo dessa ferida; num corpocadáver que é visto como uma protoescritura que testemunha o trauma. Nessa nossa cultura fascinada pelo trauma estabelece-se uma nova ética e estética da representação. (SELIGMANNSILVA, 2005, p.43 - grifo do autor)

A obra de Rubem Fonseca se enquadra nesta nova estética, visto que o autor

toca nas dores humanas mais profundas; acredita que o papel do escritor seja justamente desvelar aquilo que incomoda, aquilo que agride ao ser posto no centro da cena. Diante disso, é possível dizer que a brutalidade é tanto tema quanto opção estética de Fonseca; a violência não está somente na matéria narrada, mas também na própria forma de narrar, que é crua, sintética, desprovida de supérfluos e comentários moralizantes, edificantes. (GONÇALVES, 2006, p.8-9)

O abjeto propõe um apagamento de fronteiras, uma inquietação causada pela negação da forma, pela deformação. A ambiguidade expressa nos temas abjetos pode estabelecer uma ponte com a ambiguidade formal do miniconto, por exemplo: a forma através da qual o miniconto "Os inocentes" é estruturado se assemelha à poesia, reforçando o caráter ambivalente do miniconto enquanto gênero. O tema da morte ora é acentuado, ora atenuado. Primeiramente o autor joga uma lente de aumento sobre o cadáver, nos apresentando cada um dos pormenores físicos da superfície do corpo em putrefação de maneira crua e direta. Em seguida todo o horror da imagem lentamente construída do cadáver é suavizado de maneira irônica que beira o humor com a 
chegada em cena da família que se regozija a ocupar, sem saber, o espaço deixado pelo corpo putrefato recém-carregado. A agilidade característica do miniconto não se apresenta neste caso. Ao invés de uma ação rápida, nós temos uma apresentação lenta. Ao invés do fast-forward temos a impressão de ver a cena através das lentes de uma câmera congelada, em close, fechada no corpo. Depois da retirada do corpo da praia, o tempo se acelera e rapidamente o local é tomado por uma infinidade de pessoas e, finalmente, pela família que passará a ocupar o lugar do corpo. Gonçalves comenta a respeito da estratégia do autor:

A escolha dos narradores ilustra a maneira como o autor é sintético na construção dos contos: [...] a história corre sem que haja uma voz exterior à trama a interpretar e comentar os fatos. É como se eles acontecessem por si próprios, diante do leitor, em tempo real, com a ficção assumindo um caráter performativo. É o que Hélio Pólvora (1971) chama de 'coisa acontecendo'. (2006, p.66)

Algo semelhante se passa em "Ele canta". Atestamos uma narração que se desenrola no tempo presente da ação do olhar do narrador, como pode ser visto no seguinte trecho: "No final da tarde, quando está mais fresco, os parasitas sobem até lá. Pode reparar. Estão lá agora, comendo a polpa de cal e de cinza" (RAMOS, 2001, p.13). O narrador parece não ter tempo para avaliar as informações que apresenta ao leitor, está tão desamparado quanto nós frente a algo inominável. Durante a leitura assumimos o lugar de testemunha, somos postos frente a frente com algo inefável, que não pode ser falado, mas apenas mostrado, assim como tudo aquilo que é abjeto. Fernandes compara a obra plástica 
de Nuno Ramos, repleta de materiais orgânicos, e sua obra escrita: “Em seus poemas, ele canta materiais análogos ao que emprega em sua obra plástica com efeito oposto, porém: escrita a matéria, ela torna-se no inorgânico, no desarticulado, no inanimado; a palavra, pois, rebaixa, ultraja" (FERNANDES, 2018, p.138).

Através da tentativa de circundar o inominável a partir da escrita podemos retornar à teoria do fantástico. Roas se apropria de uma sentença de Bioy Casares, que define de forma belíssima a condição do texto fantástico: "Na borda das coisas que não compreendemos plenamente, inventamos contos fantásticos para aventurar hipóteses ou para compartilhar com outros as vertigens da nossa perplexidade" (CASARES, Apud ROAS, 2014, p.89). Perplexidade esta direcionada à nossa própria realidade. Bessière afirma que

- fantástico dramatiza a constante distância que existe entre o sujeito e o real [...] fato de que sua ocorrência, positiva ou efetiva, apareça questionada explícita ou implicitamente, apresentada como transgressora de uma noção de realidade enquadrada dentro de certas coordenadas histórico-sociais muito precisas. (Apud ROAS, 2014, p.47)

Roas conclui que o fantástico, permanecendo no tempo através de suas modificações formais e temáticas, "é literatura pós-moderna" (ROAS, 2014 p.106). O autor afirma que o conflito continua a constituir o centro do modo narrativo, mesmo levando em consideração as novas concepções acerca da realidade. Roas afirma: "Os autores atuais se valem do fantástico não apenas para denunciar a arbitrariedade de nossa concepção do real, mas 
também para revelar a estranheza do nosso mundo" (ROAS, 2014, p.106). Por fim, o autor conclui:

o mundo da narrativa fantástica contemporânea continua sendo nosso mundo, e nós continuamos nos vendo representados no texto. Nossos códigos de realidade [...] não apenas deixam de funcionar quando lemos textos fantásticos, como também atuam sempre como contraponto, como contraste de fenômenos cuja presença impossível problematiza a ordem precária ou a desordem em que fingimos viver mais ou menos tranquilos. (ROAS, 2014, p.108)

Jorge Schwartz afirma que o acontecimento fantástico

vive apenas através da linguagem. Sua existência [...] é puramente linguística, criando assim um paradoxo em relação com mundo real que a constitui. Fundamentado num universo empírico, sobrevive apenas na dimensão da escritura, tornando-se paradoxal pela sua capacidade de nomear aquilo que é e não é ao mesmo tempo. (1981, p.54-55 - grifo do autor)

A fim de dar conta de tal tarefa, o escritor do fantástico necessita empregar uma série de recursos linguísticos. Ao analisar os contos fantásticos, Roger Bozzetto (Apud ROAS, 2014), David Roas (2014), Remo Ceserani (2006) e Rosalba Campra (Apud ROAS, 2014) percebem o uso recorrente de uma série de ferramentas literárias que permitem a apropriação do irreal no interior do texto. Cada um desses autores construiu uma categorização dos elementos formais recorrentes no gênero. Rosalba Campra (Apud ROAS, 2014) está entre os autores que buscaram estabelecer uma diferenciação entre os textos fantásticos, tradicionais e contemporâneos, tendo como 
foco a reelaboração da linguagem. A autora delimita a transgressão linguística como elemento do fantástico. Campra afirma que houve uma importante mudança na linguagem fantástica a partir do século $X X$ :

a passagem do fantástico como fenômeno da percepção (em que o componente semântico domina), próprio do século XIX, ao fantástico como fenômeno da escrita, da linguagem. Um predomínio do nível verbal que está diretamente relacionado com uma tendência geral do contexto literário. (Apud ROAS, 2014, p.72-73)

A impossibilidade de verificação empírica do evento insólito nos remete de volta a Roas, quando este afirma que as manobras literárias do conto fantástico visam anunciar o indizível, a alteridade, porém,

sem poder enunciá-lo [...] e por isso se converte em uma forma de oposição social subversiva que se contrapõe à ideologia do momento histórico em que se manifesta. O fantástico revela as relações problemáticas que se estabelecem entre a linguagem e a realidade, pois tenta representar 0 impossível. (ROAS, 2014, p.175)

Roas resgata em Bellemin-Noël a noção de uma "retórica do indizivel" (BELLEMIN-NOËL, Apud ROAS, 2014, p.172), referente aos recursos narrativos necessários para dar conta, textualmente, do indescritível. Esta escrita marca o incrível, o excepcional. Já Roger Bozzetto (Apud ROAS, 2014, p.172) elenca uma série de "operadores de confusão", configurados por recursos discursivos e temáticos "que intensificam a incerteza diante da percepção do fenômeno impossível" (BOZZETTO, Apud ROAS, 2014, p.172) e que são recorrentes na escrita do fantástico: 
metáforas, sinédoques, comparações, paralelismos e expressões ambíguas do tipo 'pensei ter visto', 'acho que vi', 'era como se', assim como a utilização reiterada de adjetivos de forte conotação, como 'sinistro', 'fantasmagórico', 'aterrorizante', 'incrivel' e outros desse mesmo campo semântico. (BOZZETTO, Apud ROAS, 2014, p.172)

Roas aponta que a utilização de tais recursos é chamada por Mellier de "fantástico da indeterminação" (ROAS, 2014, p.172). Como exemplo, o autor cita as construções impossíveis de Lovecraft:

O autor americano costuma recorrer a construções em oximoro ou paradoxo nas descrições dos seres e fenômenos sobrenaturais que povoam seus contos: 'arquitetura obscena', 'ângulos obscenos', 'antiguidade maléfica', 'campanários leprosos', 'pestilentastempestades', 'concertonauseabundo'... Sintagmas que sugerem algo impossível em nossa realidade por meio de substantivos e adjetivos que, de forma independente, correspondem a objetos e propriedades provenientes dessa realidade. (ROAS, 2014, p.174)

Por fim, podemos concluir que tanto no texto de Rubem Fonseca quanto no de Nuno Ramos encontramos uma temática da abjeção. $\mathrm{O}$ texto de Fonseca apresenta uma narração em prosa diagramada de maneira a se assemelhar a um poema. Já o texto de Nuno Ramos é enquadrado enquanto poema, tanto pelo autor quanto pela crítica, mas é diagramado de maneira semelhante a um texto em prosa. A partir destas reflexões concluímos que a hibridação, a indeterminação, a ambiguidade e o apagamento das fronteiras tornam o miniconto um espaço privilegiado para a presença do tema da abjeção na literatura e se apresenta enquanto uma boa opção para demarcar tanto o texto de Rubem Fonseca, quanto o de Nuno Ramos. 


\section{REFERÊNCIAS}

BOSI, Alfredo (2002). O conto brasileiro contemporâneo. São Paulo: Ed. Cultrix. CESERANI, Remo (2006). O fantástico. Curitiba: UFPR.

ECO, Umberto (2007). História da feiura. Rio de Janeiro: Record.

EULALIO, Alexandre (1965). "Animais de estimação". O Globo, Rio de Janeiro, 23 ago. p.3.

FERNANDES, Pádua (2004). "Ele cala: a poesia de Nuno Ramos". Rodapé. São Paulo, 3, 137-144.

FONSECA, Rubem (1999). Lúcia McCartney. São Paulo: Companhia das Letras.

GODOY, Abilio M (2009). Negatividade, fatalidade e aporia: uma visão trágica do mundo nos contos de Rubem Fonseca. (Dissertação de Mestrado em Letras). Universidade de São Paulo. São Paulo.

GONÇALVES, Rachel V. de M (2006). Pequenas criaturas e o efeito de real: a estética da crueldade em Rubem Fonseca. (Dissertação de Mestrado em Letras). Universidade Estadual Paulista. Araraquara, São Paulo.

HOHLFELDT, Antonio Carlos (1988). Conto brasileiro contemporâneo. Porto Alegre: Mercado aberto.

KRISTEVA, Julia (1980). Pouvoirs de l'horreur: Essai sur l'abjection. Paris: Éditions du Seuil.

PÓLVORA, Hélio (1971). "Rubem Fonseca”. In: A força da ficção. Petrópolis: Vozes. RAMOS, Nuno (2001). "Ele canta” In O pão do corvo. São Paulo. 34.ed, p.13-14.

ROAS, David (2014). A ameaça do fantástico: aproximações teóricas. Trad. Julián Fuks. São Paulo: Editora Unesp.

SCHWARTZ, Jorge (1981). Murilo Rubião: a poética do uroboro. São Paulo: Ática. SELIGMANN-SILVA (2005). O local da diferença. São Paulo, 34.ed.

SPALDING, Marcelo (2008). Os cem menores contos brasileiros do século e a reinvenção do miniconto na literatura brasileira contemporânea. (Dissertação de Mestrado em Literaturas Brasileira, Portuguesa e Luso-africanas) -. Universidade Federal do Rio Grande do Sul, Porto Alegre.

VIEIRA, Miguel Heitor Braga (2015). "Origens do miniconto brasileiro contemporâneo". Revista Língua \& Literatura, 17, 66-80. 